\title{
The Temporal Structure of Reinforcement: An Analysis of Brain-Stimulated Reward
}

\author{
R. J. KATZ \\ Mental Health Research Institute, Department of Psychiatry, \\ University of Michigan Medical Center, Ann Arbor, Michigan 48109
}

\begin{abstract}
Adult male Sprague-Dawley rats were implanted with electrodes aimed at the medial forebrain bundle. The electrodes were connected to brushings which permitted chronic electrical self-stimulation. Over time, the rats developed episodic response patterns (response bursts). Bursting for self-stimulation was demonstrated mathematically, and analyzed to establish contributions of drivelike and incentive-like processes to burst parameters. An incentive-priming model appeared to operate under steady state conditions but a drive-like process was detected when the steady state was perturbed. Thus, self-stimulation is not uniquely determined in accord with either a drive or an incentive model of motivation, but the precise contributions of each may be empirically tested and dissociated.
\end{abstract}

Many behaviors, when observed under steady state conditions (i.e., during periods of chronic and continual access to reinforcement, and without externally imposed manipulations of motivation) assume a nonrandom, episodic character. Spontaneous behaviors often occur as discrete bursts temporally bounded by periods of nonresponse (interburstintervals) (e.g., Collier et al., 1972; Norton, 1968; Premack \& Kintsch, 1970). Feeding and drinking occur as discrete meals (Premack \& Kintsch, 1970; Levitsky, 1974), exploratory behavior and wheel running are episodic (Norton, 1968; Premack \& Kintsch, 1970), and filial behaviors also assume a temporally discrete and bounded character (Hoffman \& Kozma, 1966; Anderson, 1972; DePaulo, 1975). Informal observations of rats maintained with chronic access to intracranial reward indicate they also eventually respond in bursts (Annau et al., 1974; Waquier, 1974; Katz, unpublished observations).

Bursting, then, appears to be prevalent in many motivated behaviors, and it is therefore of interest that the mathematical analysis of bursting patterns may offer insight into some widely used concepts in motivation theory (Norton, 1968; Premack \& Kintsch, 1970; DePaulo, 1975). Bursts, by definition, may be quantified along several mathematical 
dimensions-bursts have a distinct length, size (total number of responses), and are preceded and followed by temporally defined periods of nonresponse. At least two models of motivation may be used to describe burst-interburst relationships (i.e., drive, incentive; see below). This paper will examine self-stimulation bursting for its empirical fit to each of these two theoretical models.

Burst-interburst relationships may be organized either according to a drive-satiety principle or according to an incentive-priming principle. These two views of reinforcement have long been present in learning theory (e.g., Tolman, 1932; Hull, 1943) and their meaning in the present paper is fundamentally similar to previous formulations. Briefly a drive model of reward may be conceptualized as a homeostatic system. An internal state (or states) cumulates monotonically with time, and is discharged by self-stimulation, through the drive-reducing properties of the latter. The incentive model on the other hand is nonhomeostatic. It assumes rather that the stimulus properties of stimulation are positively reinforcing. In this last case, however, no need is satisfied. These two models make a number of unique predictions regarding the temporal characteristics of bursts. On the one hand if behavior is organized by a drive-satiety principle, then extended periods of nonresponse should allow a large accumulation of drive motivation, and this should cause an extended burst. Conversely, shorter preburst intervals should be followed by relatively weaker drives and smaller bursts. Positive correlations should therefore exist for preburst intervals and burst parameters such as length (time), or size (number of responses), provided that a drive-like process contributes to reinforcement. By similar logic, it follows that longer bursts should engender greater satiety (postburst intervals without responses) while shorter bursts should produce less satiety, and shorter postburst pausing. Significant positive correlations are therefore also predicted between burst parameters such as length and size, and postburst interval. A number of motivated states appear to be organized according to a drive-satiety model (drinking, Premack \& Kintsch, 1970; social behaviors, Latane et al., 1970, 1972; and feeding under certain specialized conditions, Balagura \& Coscina, 1968; Thomas \& Mayer, 196S; Snowden, 1969; Duncan et al., 1970; LeMagnen et al., 1973). Drive-like processes have been proposed for self-stimulation (Deutsch \& Howarth, 1963; Gallistel, 1973: Crow, 1973; Stein, 1978).

Drive-satiety models are far from universal, however, and many other behaviors appear to be normally organized according to principles of incentive and priming. The incentive view of reward suggests that a stimulation-seeking mechanism normally operates at some constant probability. At various times, defined by the immediate local probability of incentive seeking, the reward mechanism exceeds a threshold value necessary for response initiation. While an incentive view does not ex- 
plain the temporal structure of responding (bursting) and, in fact, suggests a random organization of response reflecting the probabilistic nature of incentive seeking, bursting is predicted when it is supplemented with a priming principle. The priming mechanism is postulated to operate to lower the threshold for response initiation (e.g., Edmonds et al., 1974) and make responding more likely. Clearly, if an animal responds and the response both produces reward and also primes the animal, a single response increases the likelihood of additional responding within the interval of the priming stimulus' effectiveness. If priming can further cumulate the likelihood of continued responding after an initial and randomly initiated response is further enhanced. It should be clear that since responding is randomly initiated correlations between bursts and interburst intervals are predicted to be low or absent. Many behaviors appear to utilize incentive-priming principles (e.g., feeding, under a number of conditions, Hirsch, 1973; Levitsky, 1974; Panksepp \& Ritter, 1975; ${ }^{1}$ filial behavior, Hoffman \& Kozma, 1966; DePaulo, 1975). A number of incentive models of self-stimulation have also been proposed (Stein, 1968, 1978; Trowill et al., 1969; Crow, 1973; Gallistel, 1973).

The present two models of reward are therefore distinguished by different predictions concerning burst-interburst correlations. They are also distinguished by an additional prediction concerning the sequential dependency of bursting. A drive-satiety model predicts that the longer a burst continues, the more satiated an animal becomes, and the less likely it is that the burst will continue. The probability of a burst continuing should therefore decrease as a burst progresses. The priming model predicts the opposite; responding should produce priming which should increase the probability of additional responding. As priming effects cumulate, a high constant asymptotic probability of response should occur (both models predict burst termination due to a finite probability of response which is less than one).

The purpose of the present investigation is threefold; these purposes are: (a) to establish (under steady state conditions) the existence of bursting in self stimulation in a mathematically rigorous manner, (b) to examine the relations between empirical burst-interburst correlations and sequential dependencies on the one hand, and theoretical predictions of drive and incentive models on the other, and (c) to reexamine selected burst parameters and burst-interburst relationships after the systematic perturbation of a motivational steady state through imposed abstinence from normally available stimulation.

\footnotetext{
1 The difference in appetitive behavior which determine relative consonance with drive or incentive factors include food type, ecological niche of the species under study, and imposed motivational constraints; the interested reader is referred to Levitsky, 1974 and Panksepp and Ritter, 1975, for more detailed discussion of these determinants.
} 


\section{MATERIALS AND METHODS}

\section{General Methods}

Subjects. Adult male Sprague-Dawley rats $(n=10 ; 350-575 \mathrm{~g}$ per subject; Charles River Farms, Portage, Mich.) were individually maintained with ad libitum food (Teklad $4.0 \%$ fat diet, S-0836, Teklad, Madison, Wis.) and tap water, and normal day/night cycles of $12 \mathrm{hr}$ (lights on 8:00-20:00 hr EST). The home cages were modified to allow chronic self-stimulation access.

Apparatus. The home cages utilized the design of Wolf et al., for ICS (Wolf et al., 1973; Katz et al., 1979). Standard $25 \times 18 \times 17$-cm stainlesssteel cages were modified to house a $14 \times 16-\mathrm{cm}$ plate located $14 \mathrm{~cm}$ from the cage floor. The floor served as a stimulation ground. Upward displacement of the overhead panel allowed circuit completion and stimulation delivery through a head-mounted brushing. The design allowed continuous access to the stimulation contingency, and self-stimulation without external leads through the combined contact plate/manipulandum. Stimulation consisted of a $0.3-\mathrm{sec}$ train of $60 \mathrm{~Hz}$ sinusoidal current, $50-300 \mu \mathrm{A}$ in intensity. A series of capacitors and resistances were used to assure constant current conditions.

Surgery. Subjects were anesthetized with sodium pentobarbital (intraperitoneal Nembutal $50 \mathrm{mg} / \mathrm{kg}$ ) and stereotaxically implanted with unipolar $0.025 \mathrm{~cm}$ diameter nichrome wire electrodes insulated to the tip. Electrodes were aimed at the medial forebrain bundle (coordinates from bregma $=-5.0,1.0,-8.0$ ) and were attached to a head-mounted brass brushing which was secured to the skull with stainless-steel screws and acrylic dental cement. Additional details of surgery and electrode and brushing construction may be found in Wolf et al., 1973.

Experimental procedure. A minimum of 7 days after surgery, subjects were put into the stimulation cages with current on $(50-100 \mu \mathrm{A})$. Standard shaping procedures were used to train a rearing response that brought about plate-brush contact. Over the next week, current was adjusted to maintain high stable response rates (final rates after 1 week: $3000-10,000$ $\mathrm{R} / 24 \mathrm{hr}$ ). Visual inspection of response records indicated that bursting patterns began for all subjects between Days 4 and 7, and that bursting was generally accompanied by a decrease in daily response rate. During the following 14 days of responding, bursting and daily rate stabilized. Records for the initial analysis of bursting were made between Days 22 and 27 of the experimental session. Data were collected for $12 \mathrm{hr}(20: 00-$ 8:00, i.e., normal dark cycle) at 30-sec intervals. A burst was defined as an interval with one or more responses $/ 30 \mathrm{sec}$. Consecutive intervals with 1 or more responses/30 sec were scored as a single burst, the length of which was equal to total time $/ 30 \mathrm{sec}$ (i.e., the number of $30-\mathrm{sec}$ intervals). One or more consecutive periods without responding was considered an 
interburst interval. Between Days 28 and 44, subjects were deprived of stimulation access for 1,2 , or 3 days, to allow the manipulation of drive. Deprivation sessions involved removing subjects from stimulation cages and placing them in identical cages lacking stimulation plates. Sessions were administered to subjects in counterbalanced order, and a minimum of 3 days was allowed between sessions. For all subjects the dark period immediately following 72 -hr deprivation was recorded, as above, and analyzed for changes in response pattern with respect to ad libitum conditions. Animals were then sacrificed with an overdose of Nembutal and perfused initially with $0.9 \%$ sodium chloride and then with Formolsaline-acetate solution (Luna, 1960). Brains were removed, blocked, sectioned, and stained with cresyl violet using standard histological procedures (Luna, 1960). A composite histology is included as Fig. 1.

Statistical procedure. Bursting tendency was evaluated through firstorder conditional probabilities of responding using the binomial probability expansion. Bursting was considered statistically robust for a session if the conditional probability of an interval containing a response, given one or more responses in the preceding interval, was significantly greater than the conditional probability of response when the previous $30 \mathrm{sec}$ contained no response. This method is based upon the method of Hoffman and Kozma (1966). Bivariate correlation procedures, analysis of variance, and $t$ tests were used for additional demonstrations of burst parameters and relationships. All results, unless otherwise indicated, are presented as mean \pm standard error. Finally, it should be noted that at various points in the paper, individual rather than group data are analyzed. While a number of philosophic and practical reasons may be invoked for the presentation

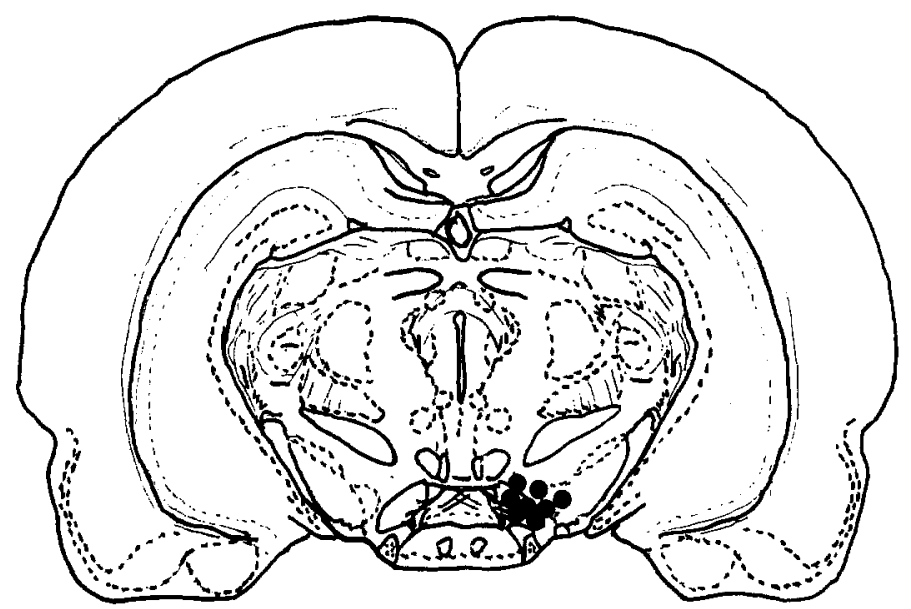

FIG. 1. Composite histology of self-stimulation sites based upon the atlas of Konig and Klippel (1967). 
of individual data (Sidman, 1960), the major impetus for selective analysis of individual performances in the present case rests with a number of practical concerns summarized in Panksepp, (1973), and Hirsch and Collier (1974). The group analysis of feeding bursts has previously been shown to systematically bias and artificially inflate a number of burstassociated relationships.

\section{Demonstration of Bursting}

To further illustrate the main features of bursting under steady state and 72-hr deprived conditions Fig. 2 presents some typical response records. In all cases the records presented were begun with the first burst of the session and continue for 100 subsequent 30 -sec intervals. Some main features of interest include the normal bursting patterns (IA; IIA) and their apparently random relation to interburst intervals. Also it may be seen that deprivation produced an increase in responding (IB; IIB). This represented a disruption of normally discrete bursting. These relationships and related findings are discussed quantitatively below.

Section 1. Previous reports have suggested bursting in chronic ICS based upon informal visual inspection of response records. As a first step in the present analysis response patterns were analyzed mathematically for bursting. Differential conditional probabilities were computed and analyzed as described. The basic parameters of bursting and conditional probabilities are presented in Table 1. It may be seen that under ad libitum conditions, subjects show reliable bursting, with a median 50 bursts per session (range 41-69), a median burst length of 3.7 intervals (range 2.8-

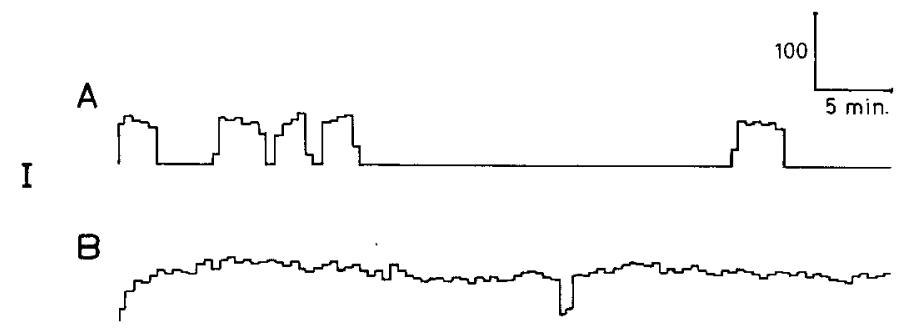

A

II

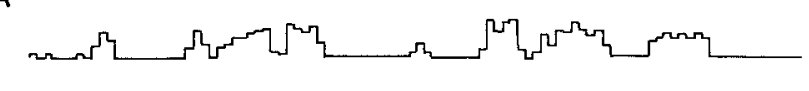

$B$

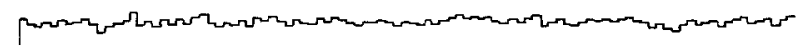

FIG. 2. Patterns of bursting (individual records). A, patterns of response under steady state nondeprived condition; B, patterns of response after $72 \mathrm{hr}$ of deprivation. In all records the first response in the session is taken as time 0 and the subsequent $100 \mathrm{~min}$ are presented. 
6.5), and a median size of 106 (range 85-348). The robustness of bursting is obvious from an examination of the final columns of Table 1 . In each case the likelihood of an interval with a response occurring is higher when it is preceded by a previous response-containing interval than when it is not so preceded $(p<.001$ by binomial expansion; $n=10$, number of subjects).

It might be argued that a variety of systematic experimental effects might yield burst-like behavior without the actual presence of discrete bursting patterns. For example if subjects showed warm-up effects or habituation over the session then responses would cluster in early or late parts of the session, and yield sequential patterns similar to bursting. Table 2 examines sequential dependencies for the initial and final $2 \mathrm{hr}$ of the session for all subjects. No systematic changes are observed. Visual inspection of the data provided further evidence of an approximately equal distribution of bursts across the session. Warm-up or habituation effects therefore cannot account for the present results.

\section{Analysis of Burst-Interburst Dependencies}

Since robust bursting was established, the relationships of bursts and interburst intervals were investigated. Bivariate correlations were performed on individual subjects to explore systematic relationships between (a) preburst length and burst length, (b) preburst length and burst size, (c) burst length and postburst length, and (d) burst size and postburst length. Correlation scores indicate no systematically significant relationships across burst conditions; these data are included as Table 3 . One additional

TABLE 1

Analysis of Bursting in Self-Stimulation

\begin{tabular}{cccccc}
\hline \multicolumn{5}{c}{ Bursts } \\
\cline { 2 - 6 } Subject & $\begin{array}{c}\text { Mean } \\
\text { length } \\
\left( \pm \text { SEM }^{a}\right.\end{array}$ & $\begin{array}{c}\text { Mean } \\
\text { size } \\
( \pm \text { SEM })\end{array}$ & $\begin{array}{c}\text { Number/ } \\
\text { session }\end{array}$ & $\begin{array}{c}\text { Probability } \\
\text { if no } \\
\text { response }\end{array}$ & $\begin{array}{c}\text { Probability } \\
\text { if prior } \\
\text { response }\end{array}$ \\
\hline 1 & $4.5 \pm 0.5$ & $177 \pm 23$ & 39 & .05 & .88 \\
2 & $3.5 \pm 0.5$ & $102 \pm 18$ & 73 & .09 & .79 \\
3 & $6.5 \pm 1.1$ & $348 \pm 72$ & 53 & .12 & .90 \\
4 & $5.2 \pm 0.5$ & $74 \pm 22$ & 69 & .14 & .90 \\
5 & $3.5 \pm 0.4$ & $113 \pm 22$ & 61 & .20 & .95 \\
6 & $3.4 \pm 0.3$ & $91 \pm 15$ & 47 & .03 & .81 \\
7 & $3.9 \pm 0.6$ & $85 \pm 16$ & 43 & .08 & .83 \\
8 & $2.8 \pm 0.7$ & $93 \pm 17$ & 36 & .02 & .82 \\
9 & $2.8 \pm 0.2$ & $120 \pm 21$ & 54 & .06 & .86 \\
10 & $3.9 \pm 0.5$ & $109 \pm 23$ & 41 & .10 & .88 \\
\hline
\end{tabular}

${ }^{a}$ Burst length $=$ number of $30-\mathrm{sec}$ intervals, i.e., a score of $1=30 \mathrm{sec}$.

${ }^{b}$ Probability of bursting is mathematically significant via binomial expansion; $p<.01$. 
TABLE 2

Conditional Probabilities of Response at the Beginning and Close of a Session

\begin{tabular}{ccccc}
\hline Subject & $\begin{array}{c}\text { Probability } \\
\text { given } \\
\text { nonresponse, } \\
\text { hr 1-2 }\end{array}$ & $\begin{array}{c}\text { Probability } \\
\text { given } \\
\text { prior } \\
\text { response }\end{array}$ & $\begin{array}{c}\text { Probability } \\
\text { given } \\
\text { nonresponse, } \\
\text { hr 11-12 }\end{array}$ & $\begin{array}{c}\text { Probability } \\
\text { given } \\
\text { prior } \\
\text { response }\end{array}$ \\
\hline 1 & 0.10 & 0.91 & 0.02 & 0.85 \\
2 & 0.09 & 0.83 & 0.28 & 0.76 \\
3 & 0.15 & 0.88 & 0.13 & 0.92 \\
4 & 0.20 & 0.78 & 0.08 & 0.95 \\
5 & 0.22 & 0.90 & 0.18 & 0.73 \\
6 & 0.05 & 0.94 & 0.08 & 0.90 \\
7 & 0.06 & 0.65 & 0.10 & 0.79 \\
8 & 0.05 & 0.72 & 0.09 & 0.88 \\
9 & 0.16 & 0.76 & 0.13 & 0.82 \\
10 & 0.08 & 0.89 & 0.20 & 0.66 \\
\hline
\end{tabular}

set of correlations was calculated to examine the utility of a dynamic response model of burst accommodation, i.e., whether preburst interval correlated with response rate in the first $30 \mathrm{sec}$ of the burst. Correlations ranged from -.36 to +.19 . For only one subject (No. 4) was the correlation significant $(r=-.36, p<.05)$ and this correlation indicated a significantly lower initial rate of response with increased deprivation.

\section{Additional Analysis of Sequential Dependency-Burst Length}

To further test the nature of sequential dependency in ICS bursting, data from 20 bursts chosen at random from each subject were pooled across subjects. Analysis of bursting persistence was carried out by

TABLE 3

Burst-Interburst Relationships in ICS (Correlations)

\begin{tabular}{ccccc}
\hline Subject & $\begin{array}{c}\text { Preburst- } \\
\text { burst length }\end{array}$ & $\begin{array}{c}\text { Preburst } \\
\text { length-burst } \\
\text { size }\end{array}$ & $\begin{array}{c}\text { Burst } \\
\text { length-post- } \\
\text { burst length }\end{array}$ & $\begin{array}{c}\text { Burst } \\
\text { size-post- } \\
\text { burst length }\end{array}$ \\
\hline 1 & -0.09 & -0.08 & -0.01 & 0.02 \\
2 & 0.07 & 0.01 & -0.09 & -0.10 \\
3 & $0.32^{*}$ & 0.27 & 0.14 & 0.14 \\
4 & 0.07 & -0.06 & -0.13 & -0.10 \\
5 & -0.04 & -0.13 & -0.18 & -0.16 \\
6 & -0.05 & 0.03 & 0.08 & -0.02 \\
7 & 0.05 & 0.07 & -0.22 & -0.30 \\
8 & 0.22 & 0.21 & -0.30 & -0.28 \\
9 & -0.01 & 0.00 & -0.16 & -0.14 \\
10 & 0.03 & 0.00 & -0.05 & -0.01 \\
\hline
\end{tabular}

${ }^{*} p<.05$ (note two significant correlations are expected by $\alpha$-error and repeated testing). 
dividing all bursts of size $n+1$ or greater by all bursts of size $n$ or greater. This may be taken as a ratio of responses per opportunity to respond. Clearly the higher the value of $(n+1) / n$ the more likely it is that responses continue over time. It is evident in Fig. 3 that as burst size increases, the probability of continuing a given burst rises.

\section{Discussion of Steady State Behavior}

Under steady state conditions bursting appears to reflect incentive motivational factors. Moreover, analysis of sequential dependencies of responding indicates that exposure to stimulation increases response probability. These findings offer novel verification of some postulated ICS mechanisms. It might be questioned whether the present results may be generalized to conditions where drive is increased above steady state levels. I have previously reported a means of inducing self-stimulation drive (Katz et al., 1979) to further examine the issue of drive in ICS; section two examines responding after deprivation.

\section{Behavior after Imposed Deprivation}

Section 2. Previous reports from this laboratory indicate that rats tend to seek intracranial stimulation in a manner consonant with drive-satiety principles after systematic perturbations. Subjects maintain a fairly constant day-to-day rate of stimulation, and when they are denied stimulation access, they tend to compensate upon their next exposure by selfstimulating more (Katz et al., 1978). To investigate the nature of the stimulation-seeking drive, subjects were deprived of stimulation for varying periods of time (1, 2, 3 days). In addition to demonstrating a systematic compensatory change in ICS through daily records, the behavior of all subjects after 3 days of deprivation was analyzed for changes in the temporal structure of stimulation seeking. The 3-day session was utilized because the most reliable augmentation of rate has previously been obtained using this period (Katz et al., 1979).

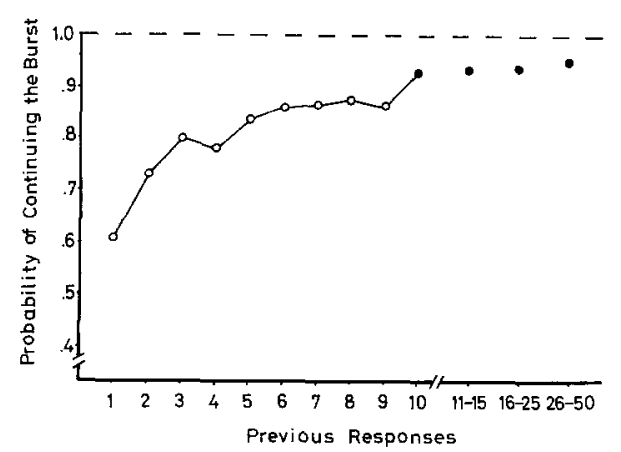

Frg. 3. Sequential dependency of ICS bursting. Burst persistence established by a ratio of $(n+1) / n$ for burst responses, $F(12,179)=7.8$ by analysis of variance, $p<.01$. 


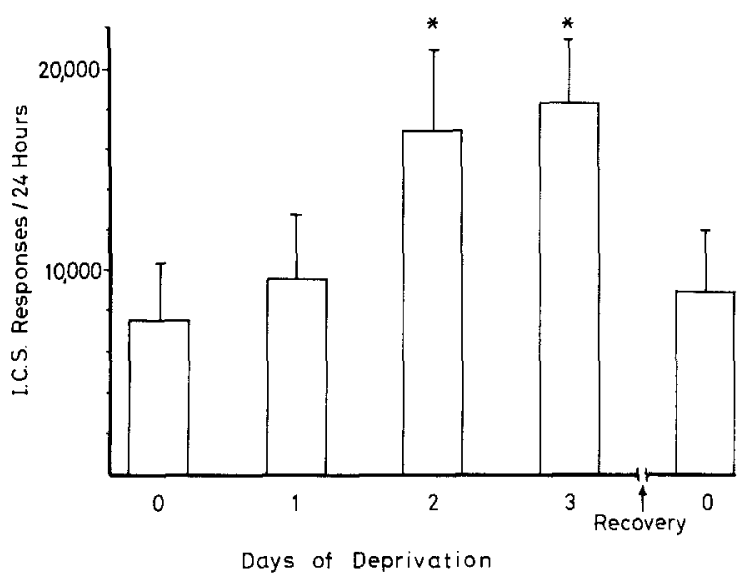

Fro. 4. Effects of ICS deprivation upon subsequent stimulation-seeking $(n=10)$. Restriction of ad libitum access to ICS causes a rebound compensation, mean \pm SEM.

\section{RESULTS}

Figure 4 indicates that systematic deprivation produces a monotonic increase in subsequent stimulation seeking (one-way repeated measures ANOVA; $F 3,27=14.3, p<.001$ ). Initial visual inspection and subsequent statistical analysis of individual subjects' records indicate a number of changes were involved in the accommodation to reduced stimulation access. Figures and analysis are presented below.

\section{Effects of Deprivation upon Burst Parameters}

Burst parameters of deprived subjects are presented in Table 4. All subjects showed consistently altered response patterns consisting of increased burst length and size, and decreased burst number. Withinsubject changes were not significant due to large standard errors. When examined as a group, however, increases in burst length and decreases in burst number proved to be significant $(t$ tests for related measures (9) $=$ $3.9,3.5$, respectively: $p<.05$ ). Changes in conditional probabilities were also significantly altered by deprivation $(t(9)=2.6,4.3$, respectively; $p<$ .05 ). Analysis of correlations between preburst interval on the one hand, and burst length and size on the other ranged from -.16 to +.20 ; no correlations were significant (data not presented separately). Analysis of correlations between burst size and length, and postburst length indicated only one rat (No. 3) showed a significant correlation ( $r=.33$ for burst size and postburst pausing; $p<.05$ by Fisher's transformation). Remaining burst-postburst correlations ranged from -.20 to +.19 (data not presented separately). Finally, Table 5 presents the mechanism of the observed changes in burst parameters. For all subjects, return to cages after 
TABLE 4

Analysis of Bursting after Stimulation Deprivation

\begin{tabular}{rrrrrr}
\hline \multicolumn{5}{c}{ Bursts } \\
\cline { 2 - 6 } & $\begin{array}{c}\text { Mean } \\
\text { length } \\
( \pm \text { SEM })\end{array}$ & $\begin{array}{c}\text { Mean } \\
\text { size } \\
( \pm \text { SEM })\end{array}$ & $\begin{array}{c}\text { Number } \\
\text { session }\end{array}$ & $\begin{array}{c}\text { Probability } \\
\text { if no } \\
\text { response }\end{array}$ & $\begin{array}{c}\text { Probability } \\
\text { if prior } \\
\text { response }\end{array}$ \\
\hline 1 & $7.2 \pm 31$ & $296 \pm 126$ & 30 & .05 & .95 \\
2 & $8.1 \pm 4.1$ & $478 \pm 383$ & 47 & .03 & .93 \\
3 & $13.1 \pm 4.7$ & $966 \pm 756$ & 22 & .02 & .97 \\
4 & $7.5 \pm 4.1$ & $466 \pm 390$ & 31 & .07 & .96 \\
5 & $5.9 \pm 2.9$ & $387 \pm 268$ & 43 & .09 & .98 \\
6 & $6.7 \pm 3.3$ & $213 \pm 73$ & 38 & .01 & .89 \\
7 & $5.6 \pm 2.7$ & $125 \pm 40$ & 33 & .03 & .89 \\
8 & $5.5 \pm 3.2$ & $515 \pm 424$ & 26 & .02 & .94 \\
9 & $5.1 \pm 2.8$ & $226 \pm 103$ & 41 & .03 & .95 \\
10 & $7.2 \pm 2.9$ & $360 \pm 248$ & 40 & .04 & .96 \\
\hline
\end{tabular}

TABLE 5

Selected Burst Parameters prior to and after Stimulation Deprivation

\begin{tabular}{ccccc}
\hline Subject & $\begin{array}{c}\text { Maximum } \\
\text { burst } \\
\text { length prior }\end{array}$ & $\begin{array}{c}\text { Maximum } \\
\text { burst } \\
\text { length after }\end{array}$ & $\begin{array}{c}\text { Intervals with } \\
\text { responding } \\
\text { in the initial } \\
60 \text { min of a } \\
\text { session prior }\end{array}$ & $\begin{array}{c}\text { Intervals with } \\
\text { responding } \\
\text { in the initial } \\
60 \text { min of a } \\
\text { session after }\end{array}$ \\
\hline 1 & 15 & 145 & 41 & 120 \\
2 & 19 & 217 & 59 & 120 \\
3 & 50 & 193 & 51 & 120 \\
4 & 18 & 191 & 37 & 120 \\
5 & 17 & 97 & 36 & 97 \\
6 & 8 & 115 & 31 & 115 \\
7 & 12 & 209 & 25 & 79 \\
8 & 65 & 66 & 22 & 85 \\
9 & 6 & 73 & 45 & 107 \\
10 & 12 & 107 & 42 & $108+5^{* *}$ \\
\hline Mean \pm sem & $22 \pm 6$ & $141 \pm 18^{*}$ & $38+3$ & \\
\hline
\end{tabular}

a Maximum burst occurred within the first hour of session for all subjects.

${ }^{b}$ In all cases includes some portion of maximum burst.

${ }^{*} t=6.2 ; p<.01$ compared to steady state; $* * t=11.3 ; p<.001$ compared to steady state. 
deprivation caused an initial extended burst. This burst, which was significantly longer than any steady state burst $(t=6.2, p<.01)$, began within the first $60 \mathrm{~min}$ of reintroduction and was superseded by bursting patterns no different than those found under steady state conditions.

\section{GENERAL DISCUSSION}

Many behaviors appear to achieve a steady state organization of bursting (see above), and self-stimulation is one such behavior. The present paper analyzed self stimulation bursting for its motivational significance, and it was apparent that (a) bursting was a robust and statistically meaningful phenomenon, (b) bursting parameters did not reflect drive, at least under steady state conditions, and (c) despite this, at least some aspects of self-stimulation bursting proved to be drive-responsive. Many theoretical analyses of brain-stimulated reward have made use of the concepts of drive and incentive (e.g., Olds, 1962; Trowill et al., 1969; Crow, 1973; Rolls, 1975; Stein, 1968, 1978). The present results suggest the utility of an incentive-priming interpretation for MFB self-stimulation under steady state conditions. It is possible that other sites or other reward paradigms might be more consonant with drive principles, and certainly it must be emphasized that drive does influence self-stimulation when imposed as a perturbation of steady state activity. Nonetheless, the incentive-priming model of reward appears to gain empirical support from a bursting analysis.

Two additional points might be made concerning the present results, and both concern the normal absence of a drive-like process. It is perhaps not surprising that drive is not a major contributing factor to selfstimulation patterns when drive is at a normally low level. The first experiment, by allowing ad libitum access to stimulation, may have minimized drive-like factors. Perhaps one reason normal steady state performance reflects incentive-priming to the degree it does rests with testing conditions that might favor low-drive-high-incentive response patterns. On the other hand, however, when animals were deprived of stimulation, they showed an initial response that reflected stimulation loss, but no significant correlations over a standard testing session. When drive was imposed, therefore, it produced a transient effect that was rapidly superseded by a return to incentive-mediated performance. It must be kept in mind that the bulk of self-stimulation studies are carried out with limited access to stimulation. Such conditions might conceivably increase the contribution of drive.

We feel the present results reflect the following model of selfstimulation. An incentive mechanism controls the normal seeking of reinforcement. In addition a priming mechanism controls local patterning, once reinforcement has been sought. Finally an additional mechanism acting over extended periods of time controls an overall level of incentive 
seeking. This long-term mechanism has at least some drive-like properties. To respond to the initially posed question concerning the normal motivational control of brain-stimulated reinforcement, then, it appears that several mechanisms must be considered. The motivational control of ICS is in part a function of the parameters of a testing situation.

It might be asked in conclusion whether the present results are in fact analogous to biological rewards since the latter are known to produce peripheral satiety signals (e.g., thirst, Fitzsimmons, 1972; hunger, LeMagnen et al. 1971) while there is no reason to assume such for central reward. Self-stimulation may lack the peripheral concomitants of other biological rewards that normally might serve to regulate burst size, frequency, or burst-interburst relations. This is possible and may represent a difference between predominantly central reward on the one hand, and other biological motivations on the other. It should be noted, however, that analyses similar to the present, using food motivation, have not necessarily found expected drive-like correlations (e.g., Panksepp and Ritter, 1975; Hirsch, 1973). Therefore, an absence of peripheral humoral controls is not necessarily a determinant of the present low levels of correlation or patterns of sequential dependency.

In conclusion, it might be noted that the present results bear a remarkable similarity to the findings of Collier and colleagues (e.g., Collier et al., 1972; Levitsky, 1974). We have previously commented upon the similarity of feeding and self-stimulation mechanisms. Our present results confirm and extend previous observations.

\section{ACKNOWLEDGMENTS}

I gratefully acknowledge postdoctoral support provided by the National Institute of Mental Health (Grant MH07417 through the Mental Health Research Institute). The technical assistance of Giulio Baldrighi and Kevin Roth and editorial assistance of Cindy Reynolds and Ruth Koerber is also acknowledged with gratitude. The analytic techniques used in this paper were brought to my attention by Drs. H. S. Hoffman and Peter DePaulo of Bryn Mawr College. Were it not for many conversations with them, and the generous sharing by Dr. DePaulo of both his master's and doctoral theses using the same techniques to analyze filial behavior, the present report would have been impossible.

\section{REFERENCES}

Anderson, J. W. (1972). Attachment behavior out of doors. In N. S. Jones (Ed.), Ethological Studies of Child Behavior. London: Cambridge Univ. Press.

Annau, Z., Heffner, R., Koob, G. F. (1974). Electrical self-stimulation of single and multiple loci: long term observations. Physiology and Behavior, 13, 281-290.

Balagura, S., \& Coscina, D. V. (1968). Periodicity of food intake as measured by an operant response. Physiology and Behavior, 3, 641-643. 
Collier, G., Hirsch, E., \& Hamlin, P. H. (1972). The ecological determinants of reinforcement in the rat. Physiology and Behavior, 9, 705-716.

Crow, T. J. (1973). Catecholamine-containing neurones and electrical self-stimulation. 2. A theoretical interpretation and some psychiatric implications. Psychological Medicine, 3, 66-73.

DePaulo, P. (1975). Motivational Aspects of Attachment Behavior in the Context of Imprinting. Unpublished master's thesis. Bryn Mawr, Pa.: Bryn Mawr College.

Deutsch, J. A., \& Howarth, C. I. (1963). Some tests of a theory of intracranial selfstimulation. Psychological Review. 70, 444-460.

Dixon, W. J., \& Massey, F. J. (1969). Introduction to Statistical Analysis (3rd ed.). New York: McGraw-Hill.

Duncan, I. J. W., Duncan, A. R., Hughes, B. O., \& Wood-Gush, D. G. M. (1970). The patterns of food intake in female brown leghorn fowls as recorded in a Skinner box. Animal Behaviour, 18, 245-255.

Edmonds, D. E., Stellar, J. R., \& Gallistel, C. R. (1974). The parametric analysis of brain stimulation reward in the rat. II. Temporal summation in the reward system. Journal of Comparative and Physiological Psychology, 87, 860-869.

Fitzsimmons, J. T. (1972). Thirst. Physiological Review, 52, 468-561.

Gallistel, C. R. (1969). The incentive of brain stimulation reward. Journal of Comparative and Physiological Psychology, 69, 713-721.

Gallistel, C. R. (1973). Self-stimulation: The neurophysiology of reward and motivation. In J. A. Deutsch (ed.), The Physiological Basis of Memory. New York: Academic Press.

Hirsch, E. (1973). Some determinants of intake and patterns of feeding in the guinea pig. Physiology and Behavior, 11, 687-704.

Hirsch, E., Collier, G. (1974). The ecological determinants of reinforcement in the guinea pig. Physiology and Behavior, 12, 239-249.

Hoffman, H. S., \& Kozma, F., Jr. (1966). Behavioral control by an imprinted stimulus: long term effects. Journal of the Experimental Analysis of Behavior, 10, 495-501.

Hull, C. L. (1943). Principles of Behavior. New York: Appleton-Century.

Katz, R. J., Baldrighi, G., \& Carroll, B. J. (1977). Effects of nomifensine (HOE 984) upon psychomotor activity and intracranial self stimulation in the rat. Pharmacology Biochemistry and Behavior, 7 (3), 269-272.

Katz, R. J., Baldrighi, G., \& Roth, K. (1979). Appetitive determinants of self stimulation. Behavioral Biology, 23, 500-508.

Konig, J. F. R., \& Klippel, R. A. (1967). The rat brain: A stereotaxic atlas of the forebrain and lower parts of the brain stem. Kreiger: Huntington, N.Y.

Latane, B., Cappell, H., \& Joy, V. (1970). Social deprivation, housing density, and gregariousness in rats. Journal of Comparative and Physiological Psychology, 70, 221-227.

Latane, B., Nesbitt, P., Eckman, J., \& Rodin, J. (1972). Long and short-term social deprivation and sociability in rats. Journal of Comparative and Physiological Psychology, 81, 69-75.

Le Magnen, J., Devos, M., Gaudilliere, J. P., Louis-Sylvestre, J., \& Tallon, S. (1973). Role of a lipostatic mechanism in the regulation by feeding of energy balance in rats. Journal of Comparative and Physiological Psychology, 84, 1-23.

Levitsky, D. A. (1974). Feeding conditions and intermeal relationships. Physiology and Behavior, 12 (5), 779-787.

Luna, L. G. (1960). Manual of Histological Staining Methods of the Armed Forces Institute of Pathology. New York: McGraw-Hill.

Norton, S. (1968). On the discontinuous nature of behavior. Journal of Theoretical Biology, 21, 229-243.

Olds, J. (1962). Hypothalamic substrates of reward. Psychological Review, 42, 554-604. 
Panksepp, J. (1973). Reanalysis of feeding patterns in the rat. Journal of Comparative and Physiological Psychology, 82, 78-94.

Panksepp, J., \& Ritter, M. (1975). Mathematical analysis of energy regulatory patterns of normal and diabetic rats. Journal of Comparative and Physiological Psychology, 89 (9), $1019-1028$.

Premack, D., \& Kintsch, W. A. (1970). A description of free responding in the rat. Learning and Motivation, 1, 321-336.

Rolls, E. T. (1975). The Brain And Reward. Oxford: Pergamon Press.

Sidman, M. (1960). Tactics of Scientific Research. New York: Basic Books.

Snowden, C. T. (1969). Motivation, regulation and the control of meal parameters with oral and intragastric feeding. Journal of Comparative and Physiological Psychology, 69, 91-100.

Stein, L. (1968). Chemistry of reward and punishment. In D. H. Efron (ed.), Psychopharmacology: A Review of Progress, 1957-1967, pp. 105-123. Washington, D.C.: U.S. Govt. Printing Office.

Stein, L., (1978). Reward transmitters: Catecholamines and opioid peptides. In M. A. Lipton, A. DiMascio, and K. F. Killam, (eds.), Psychopharmacology: A Generation of Progress, pp. 569-583. New York: Raven.

Thomas, D. W., \& Mayer, J. (1968). Meal taking and regulation of food intake by normal and hypothalamic hyperphagic rats. Journal of Comparative and Physiological Psychology, 66, 642-653.

Tolman, E. C. (1932, reprinted 1967). Purposive Behavior in Animals and Men. New York: Appleton-Century-Crofts.

Trowill, J. A., Panksepp, J., \& Gandelman, R. (1969). An incentive model of rewarding brain stimulation. Psychological Review, 76, 264-281.

Waquier, A. (1974). Circadian rhythm of brain self-stimulation in rats and resistance to long-term effects of psychopharmacological substances. Journal of Interdisciplinary Cycle Research, 5 (3-4), 340-346.

Wolf, G., DiCara, L. V., \& Simpson, W. (1973). The contact method: A simple technique for electrical self-stimulation without external leads. Physiology and Behavior, 11 (5), 721-723. 